\title{
A Median Based Directional Cascaded with MASK FILTER FOR REMOVAL OF RVIN
}

\author{
J.K. Mandal and Aparna Sarkar \\ Department of Computer Science \& Engineering, University of Kalyani, Kalyani, Nadia, \\ West Bengal \\ Mail: \{jkm.cse@gmail.com, sarkaraparna09@gmail.com\}
}

\begin{abstract}
In this paper A Median Based Directional Cascaded with Mask (MBDCM) filter has been proposed, which is based on three different sized cascaded filtering windows. The differences between the current pixel and its neighbors aligned with four main directions are considered for impulse detection. A direction index is used for each edge aligned with a given direction. Minimum of these four direction indexes is used for impulse detection under each masking window. Depending on the minimum direction indexes among these three windows new value to substitute the noisy pixel is calculated. Extensive simulations showed that the MBDCM filter provides good performances of suppressing impulses from both gray level and colored benchmarked images corrupted with low noise level as well as for highly dense impulses. MBDCM filter gives better results than MDWCMM filter in suppressing impulses from highly corrupted digital images.
\end{abstract}

\section{KEYWORDS}

A Modified Directional Weighted Cascaded-Mask Median filter (MDWCMMF), Median Based Directional Cascaded-Mask filter (MBDCMF), PSNR, SNR, Median, gray \& color image.

\section{INTRODUCTION}

Impulse noise is often introduced into images during image acquisition and transmission [13,14]. Depending upon the noise values, it can be classified as the easier-to-restore salt-and-pepper noise and the more difficult random-valued impulse noise [10]. Among all kinds of methods for impulse noise, the median filter [11, 12] is used widely because of its high computational efficiency and effective noise suppression capability [8]. However, it uniformly replaces the gray-level value of every pixel by the median of its neighboring pixels. Consequently, some desirable details are also removed, especially when the window size is large. In order to improve the median filter, many filters with an impulse detector have been proposed. In this paper a modified filter is used for removal of random-valued impulse noise which performs well in restoration of high valued random impulse noise from both the gray and color images.

In an image, distinct gray levels are to be like their neighbors. So if a pixel value got corrupted, then considering its neighboring gray values we can restore the actual value. This filter (MBDCMF) replaces the value of a pixel by the median of gray levels of neighborhood pixels of that pixel with a certain weight ( 1 or 2$)$ and the pixels in the minimum weighted direction considering all the cascaded windows. 
The minimum weighted direction is one of the four directions (as shown in Figure.1) in which the sum of absolute differences of gray level values between the pivot(central) pixel value and its neighboring pixel values is minimum.

RGB color space is used as the basic color space for the color images. In RGB model colors are represented as a 3-D vector, with red as first element, green as second and blue as third element. The organization of this paper is as follows. The new impulse detector is formulated in section 2 . Section 3 described the filtering framework. Section 4 provides a number of experimental results to demonstrate the performance of the proposed MBDCM filter. Conclusions are drawn in section 5.

\section{IMPULSE DETECTOR}

A noise-free image consists of locally smoothly varying areas separated by edges. Here, we only focused on the edges aligned with four main directions as shown in Figure 1.

Let $\mathrm{S}_{\mathrm{k}}{ }^{(7)}(\mathrm{k}=1$ to 4$)$ denote a set of coordinates aligned with the $\mathrm{k}^{\text {th }}$ direction centered at $(0,0)$, taking $(7 \times 7)$ window, i.e.,

$\mathrm{S}_{1}=\{(-3,-3),(-2,-2),(-1,-1),(0,0),(1,1),(2,2),(3,3)\}$

$\mathrm{S}_{2}=\{(0,-3),(0,-2),(0,-1),(0,0),(0,1),(0,2),(0,3)\}$

$\mathrm{S}_{3}=\{(3,-3),(2,-2),(1,-1),(0,0),(-1,1),(-2,2),(-3,3)\}$

$\mathrm{S}_{4}=\{(-3,0),(-2,0),(-1,0),(0,0),(1,0),(2,0),(3,0)\}$

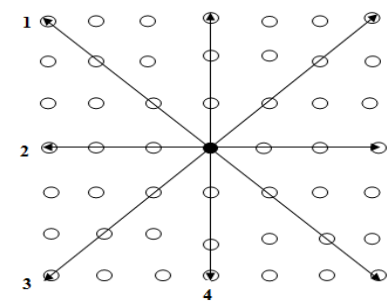

Figure 1: $\quad$ Alignment of edges in four directions in $(7 \times 7)$ window

Let $\mathrm{S}_{\mathrm{k}}^{(5)}(\mathrm{k}=1$ to 4$)$ denote a set of coordinates aligned with the $\mathrm{k}^{\text {th }}$ direction centered at $(0,0)$, taking $(5 \times 5)$ window, i.e.,

$\mathrm{S}_{1}=\{(-2,-2),(-1,-1),(0,0),(1,1),(2,2)\}$

$\mathrm{S}_{2}=\{(0,-2),(0,-1),(0,0),(0,1),(0,2)\}$

$\mathrm{S}_{3}=\{(2,-2),(1,-1),(0,0),(-1,1),(-2,2)\}$

$\mathrm{S}_{4}=\{(-2,0),(-1,0),(0,0),(1,0),(2,0)\}$

Let $\mathrm{S}_{\mathrm{k}}{ }^{(3)}(\mathrm{k}=1$ to 4$)$ denote a set of coordinates aligned with the $\mathrm{k}^{\text {th }}$ direction centered at $(0,0)$, taking $(3 \times 3)$ window, i.e.,

$\mathrm{S}_{1}=\{(-1,-1),(0,0),(1,1)\}$

$\mathrm{S}_{2}=\{(0,-1),(0,0),(0,1)\}$

$\mathrm{S}_{3}=\{(1,-1),(0,0),(-1,1)\}$

$\mathrm{S}_{4}=\{(-1,0),(0,0),(1,0)\}$ 
Now in a $7 \times 7$ window centered at $(i, j)$, for each direction, define $d_{i, j}^{(p)(k)}$ as the sum of all weighted absolute differences of gray-level values between $y_{i+s, j+t}$ and $y_{i, j}$ with $(s, t) \in S_{k}{ }^{(p)}$ for all $k$ from 1 to $4, \mathrm{p}=\{7,5,3\}$. Considering that for two pixels whose spatial distance is small, their grey-level values should be close to each other, we will weight the absolute differences between the two closest pixels with a larger value $\mathrm{w}_{\mathrm{s}, \mathrm{t}}$ is very large, it will cause that $\mathrm{d}_{\mathrm{i}, \mathrm{j}}{ }^{(\mathrm{p})(\mathrm{k})}$ is mainly decided by the differences corresponding to $\mathrm{w}_{\mathrm{s}, \mathrm{t}}$. Thus we have eq.4,

$$
\mathrm{d}_{\mathrm{i}, \mathrm{j}}{ }^{(\mathrm{p})(\mathrm{k})}=\sum \mathrm{w}_{\mathrm{s}, \mathrm{t}} *\left|\mathrm{y}_{\mathrm{i}+\mathrm{s}, \mathrm{j}+\mathrm{t}}-\mathrm{y}_{\mathrm{i}, \mathrm{j}}\right|, 1 \leq \mathrm{k} \leq 4,(\mathrm{~s}, \mathrm{t}) \in \mathrm{S}_{\mathrm{k}}^{(\mathrm{p})}
$$

\section{$(\mathrm{s}, \mathrm{t})$}

Where

$$
\begin{aligned}
& \mathrm{w}_{\mathrm{s}, \mathrm{t}}=\left\{\begin{array}{l}
2,(\mathrm{~s}, \mathrm{t}) \in \Omega^{3} \\
1, \text { otherwise }
\end{array}\right. \\
& \Omega^{3}=\{(\mathrm{s}, \mathrm{t}):-1 \leq \mathrm{s}, \mathrm{t} \leq 1\}, \\
& \mathrm{P}=\{3,5,7\} .
\end{aligned}
$$

Here, $d_{i, j}{ }^{(p)(k)}$ are the direction indexes. Each direction index is sensitive to the edge aligned with a given direction. Then, the minimum of these four direction indexes is used for impulse detection, which can be denoted as in eq. 5 .

$\mathrm{r}_{\mathrm{i}, \mathrm{j}}^{(\mathrm{p})}=\min \left\{\mathrm{d}_{\mathrm{i}, \mathrm{j}}{ }^{(\mathrm{p})(\mathrm{k})}: 1 \leq \mathrm{k} \leq 4, \mathrm{p}=\{3,5,7\}\right\}$,

We can find that by employing a threshold $T_{p},(p=\{3,5,7\})$, we can identify the impulse in each window from the noise-free pixels, no matter which are in a flat region, edge or thin line. Then, the pixel $y_{i, j}$ will be noisy if at least one of the following conditions holds

$$
\begin{array}{ll}
\text { - } & \mathrm{r}_{\mathrm{i}, \mathrm{j}}{ }^{(7)}>\mathrm{T}_{7} \\
\text { - } & \mathrm{r}_{\mathrm{i}, \mathrm{j}}{ }^{(5)}>\mathrm{T}_{5} \\
\text { - } & \mathrm{r}_{\mathrm{i}, \mathrm{j}}{ }^{(3)}>\mathrm{T}_{3}
\end{array}
$$

The pixel $\mathrm{y}_{\mathrm{i}, \mathrm{j}}$ will be noise free otherwise.

\section{FILTER}

After impulse detection, we replace the noisy pixels by the calculated median values of the window depending upon the four directions. For this first calculated the standard deviation $\sigma_{i, j}{ }^{(p)(k)}$ of grey-level values for all $\mathrm{y}_{\mathrm{i}+\mathrm{s}, \mathrm{t}+\mathrm{t}}$ with $(\mathrm{s}, \mathrm{t}) \in \mathrm{S}_{\mathrm{k}}{ }^{(\mathrm{p})}(\mathrm{k}=1$ to 4$),\{\mathrm{p}=7,5,3\}$, respectively. Let take eq. 6 as under

$\mathrm{L}_{\mathrm{i}, \mathrm{j}}^{(\mathrm{p})}=\min \left\{\sigma_{\mathrm{i}, \mathrm{j}}^{(\mathrm{p})(\mathrm{k})}: \mathrm{k}=1\right.$ to $\left.4, \mathrm{p}=\{3,5,7\}\right\}$

Since the standard deviation describes how tightly all the values are clustered around the mean in the set of pixels, $\mathrm{L}_{\mathrm{i}, \mathrm{j}}{ }^{\mathrm{p})}$ shows the pixels aligned with this direction are the closest to each other. Therefore the center value should also be close to them in order to keep the edges intact.

Three median values are calculated using the eq. 7 as below

$\mathrm{m}_{\mathrm{i}, \mathrm{j}}^{(7)}=\operatorname{median}\left\{\mathrm{w} * \mathrm{y}_{\mathrm{i}+\mathrm{s}, \mathrm{jt+}}, \mathrm{y}_{\mathrm{i}+\mathrm{p} 1, \mathrm{j}+\mathrm{q}}:(\mathrm{s}, \mathrm{t}),(\mathrm{p} 1, \mathrm{q}) \in \mathrm{S}_{\mathrm{k}}^{(7)}\right\}$

$\mathrm{m}_{\mathrm{i},{ }^{(5)}}=\operatorname{median}\left\{\mathrm{w}^{*} \mathrm{y}_{\mathrm{i}+\mathrm{s}, \mathrm{j+t}}, \mathrm{y}_{\mathrm{i}+\mathrm{p} 1, \mathrm{j}+\mathrm{q}}:(\mathrm{s}, \mathrm{t}),(\mathrm{p} 1, \mathrm{q}) \in \mathrm{S}_{\mathrm{k}}^{(5)}\right\}$

$\mathrm{m}_{\mathrm{i}, \mathrm{j}}{ }^{(3)}=\operatorname{median}\left\{\mathrm{w}^{*} \mathrm{y}_{\mathrm{i}+\mathrm{s}, \mathrm{j}+\mathrm{t}}, \mathrm{y}_{\mathrm{i}+\mathrm{p} 1, \mathrm{j}+\mathrm{q}}:(\mathrm{s}, \mathrm{t}),(\mathrm{p} 1, \mathrm{q}) \in \mathrm{S}_{\mathrm{k}}{ }^{(3)}\right\}$ 
$w= \begin{cases}2, & \text { if }-1 \leq(\mathrm{s}, \mathrm{t}) \leq 1 \\ 1, & \text { otherwise }\end{cases}$

$(\mathrm{s}, \mathrm{t})$ pixels are on the minimum direction

And

$-1 \leq(\mathrm{p} 1, \mathrm{q}) \leq 1 ;$ where $(\mathrm{p} 1, \mathrm{q}) \neq(\mathrm{s}, \mathrm{t})$.

Now, we can give the output of the proposed filter as in eq. 8 .

$\mathrm{u}_{\mathrm{i}, \mathrm{j}}= \begin{cases}\operatorname{Min}(\mathrm{u} 2, \mathrm{u} 3), & \text { if } \mathrm{L}_{\mathrm{i}, \mathrm{j}}^{(3)}=\mathrm{L}_{\mathrm{i}, \mathrm{j}}^{(5)} \\ \mathrm{u} 1, & \text { otherwise }\end{cases}$

$\mathrm{u} 1=\alpha_{\mathrm{i}, \mathrm{j}} * \mathrm{y}_{\mathrm{i}, \mathrm{j}}+\left(1-\alpha_{\mathrm{i}, \mathrm{j}}\right) * \mathrm{~m}_{\mathrm{i}, \mathrm{j}}^{(7)}$

where,

$\alpha_{i, j}= \begin{cases}0, & \text { if } r_{i, j}{ }^{(7)}>T_{7} \\ 1, & \text { if } r_{i, j}{ }^{(7)} \leq T_{7}\end{cases}$

$\mathrm{u} 2=\alpha_{\mathrm{i}, \mathrm{j}} * \mathrm{y}_{\mathrm{i}, \mathrm{j}}+\left(1-\alpha_{\mathrm{i}, \mathrm{j}}\right) * \mathrm{~m}_{\mathrm{i}, \mathrm{j}}^{(5)}$

where,

$\alpha_{i, j}= \begin{cases} \\ 0, & \text { if } \mathrm{r}_{\mathrm{i}, \mathrm{j}}{ }^{(5)}>\mathrm{T}_{5} \\ 1, & \text { if } \mathrm{r}_{\mathrm{i}, \mathrm{j}}{ }^{(5)} \leq \mathrm{T}_{5}\end{cases}$

$\mathrm{u} 3=\alpha_{\mathrm{i}, \mathrm{j}} * \mathrm{y}_{\mathrm{i}, \mathrm{j}}+\left(1-\alpha_{\mathrm{i}, \mathrm{j}}\right) * \mathrm{~m}_{\mathrm{i}, \mathrm{j}}{ }^{(3)}$

where,

$\alpha_{i, j}= \begin{cases}0, & \text { if } r_{i, j}{ }^{(3)}>T_{3} \\ 1, & \text { if } r_{i, j}{ }^{(3)} \leq T_{3}\end{cases}$

Then substitute

$\mathrm{T}=\left\{\begin{array}{l}\mathrm{y}_{\mathrm{i}, \mathrm{j}}=\mathrm{u}_{\mathrm{i}, \mathrm{j}} \\ \mathrm{T}_{3}, \text { for }(3 \times 3) \text { window } \\ \mathrm{T}_{5}, \text { for }(5 \times 5) \text { window } \\ \mathrm{T}_{7}, \text { for }(7 \times 7) \text { window }\end{array}\right.$

So, for ensuring high accuracy of the detection, we applied our method recursively and iteratively with decreasing threshold $(\mathrm{T}=\mathrm{T} * 0.8)$, starting with the value $\mathrm{T}=510$, and iterated until $\mathrm{T} \geq$ arithmetic mean of all the pixel values on the minimum direction of the corresponding window. 


\section{RESULTS}

Different gray and color (RGB) benchmark images have been taken for the experimental purpose. Noises have been injected randomly into the original images to produce noisy images. The enhancement filter restores images from these noisy images. Figure 2.a and 2.b are original benchmarked Elaine and Lenna gray images. Figure 2.c and 2.d are original benchmarks, Lenna and Baboon color images. Figure 2.e, Figure 2.g are the noisy images, with $40 \%$ and $60 \%$ noise density, of gray Lenna where PSNR is $13.93 \mathrm{~dB}$ and $12.57 \mathrm{~dB}$ respectively that of Figure $2 . \mathrm{f}$ and Figure 2.h are the filtered image using MBDCMF where the PSNR is $24.49 \mathrm{~dB}$ and $22.07 \mathrm{~dB}$ respectively. Figure 2.1 shows $40 \%$ corrupted gray Elaine benchmark image whose PSNR value is $14.13 \mathrm{~dB}$ and after applying MBDCMF on it, the PSNR obtained is $26.15 \mathrm{~dB}$ (Figure 2.j). Figure 2.k shows $30 \%$ noise integrated image of color Lenna where PSNR is 14.49. Applying MBDCMF on it PSNR increases to $25.97 \mathrm{~dB}$ (Figure. 2.1). Figure 2.m shows 60\% noisy color Lenna image, whose PSNR is $12.09 \mathrm{~dB}$. Figure 2.n is obtained from Figure 2.m after applying MBDCMF and its PSNR is $22.57 \mathrm{~dB}$. Figure 2.o shows 60\% corrupted Baboon (RGB) benchmark image whose PSNR value is $12.27 \mathrm{~dB}$ but when MBDCM filter has been applied on it, the PSNR obtained is 18.32(Figure 2.p) from where we may infer that MBDCM filter may obtain good results in random and high noise removal from gray and color images.

Table 1 shows the comparative PSNR using various filters PWMAD[4], ACWM filter[2,3], AMF[8], MDWCMMF[1] including proposed MBDCM filter applied on Lenna gray image corrupted by various percentages of noise density.

Table 2 shows the comparative PSNR using various filters AVMF[27], IIA[17], MFF[18], ATMED[22], GMED[22], TMAV[22], FSB[26], IFCF[24], MIFCF[24], EIFC[24], SSFCF[24], FIRE[18], PWLFIRE[19], DSFIRE[16], FMF[22], HAF[25], AWFM[23], MDWCMMF[1] including proposed MBDCM filter applied on color Lenna image corrupted by various percentages of noise density.

Table 3 shows the effect of applying MBDCM filter of various images corrupted by $40 \%$ noise. From the table it is also clear that the MBDCM filter works better for high value of random impulse noise.

Figure 3. shows the comparative performance of the proposed MBDCM filter applied on gray Lenna corrupted with different levels of impulses among some other existing filters.

Figure 4. shows the comparative performance of the proposed filter applied on Elaine and Goldhill images corrupted with $40 \%$ random impulses among some other existing filters.

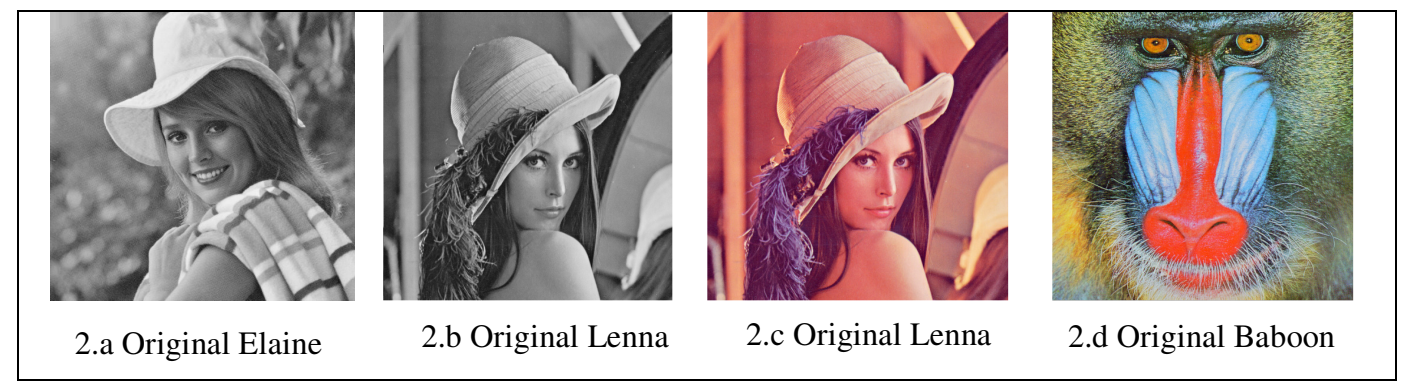


International Journal of Information Sciences and Techniques (IJIST) Vol.2, No.4, July 2012

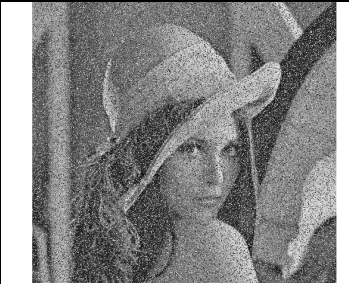

2.e $40 \%$ Noisy Lenna $\mathrm{PSNR}=13.93 \mathrm{~dB}$

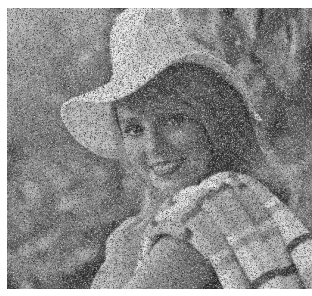

2.i $40 \%$ Noisy Elaine PSNR $=14.13 \mathrm{~dB}$

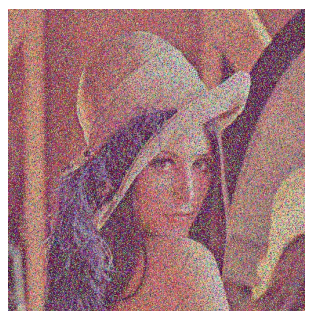

2.m 60\% Noisy Lenna $\mathrm{PSNR}=12.09$

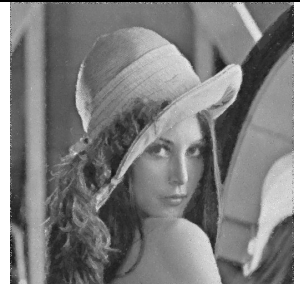

2.f Restored Lenna PSNR=24.49 dB

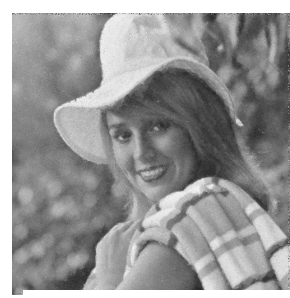

2.j Restored Elaine $\mathrm{PSNR}=26.15 \mathrm{~dB}$

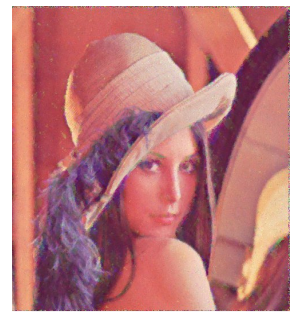

2.n Restored Lenna $\mathrm{PSNR}=22.57 \mathrm{~dB}$

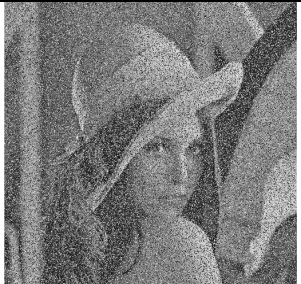

2.g 60\% Noisy Lenna $\mathrm{PSNR}=12.57$

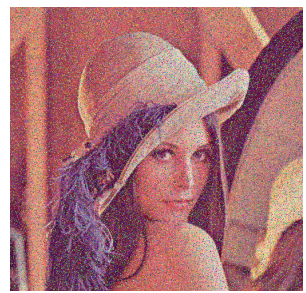

2.k 30\% Noisy Lenna $\mathrm{PSNR}=14.49$

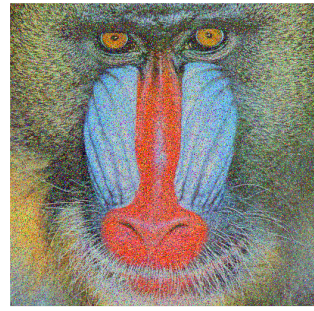

2.o 60\% noisy Baboon $\mathrm{PSNR}=12.27 \mathrm{~dB}$

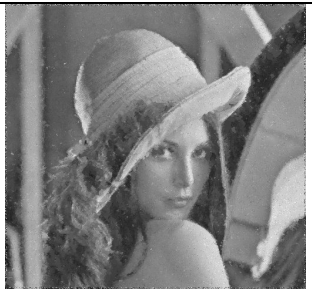

2.h Restored Lenna PSNR=22.07 dB

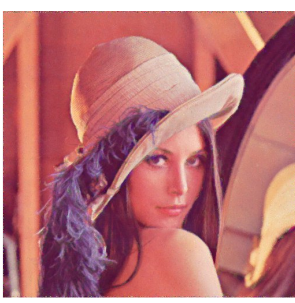

2.1 Restored Lenna $\mathrm{PSNR}=25.97 \mathrm{~dB}$

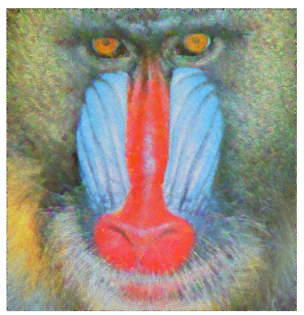

2.p Restored Baboon $\mathrm{PSNR}=18.32 \mathrm{~dB}$

Figue 2: Visual effect of results using MBDCMF on gray and colour images.

Table 1. Comparative results in PSNR of different algorithms applied to "Lenna" gray image corrupted by various rayes of Random-valued impulse noise

\begin{tabular}{|c|c|c|c|c|c|c|}
\hline \multirow[t]{2}{*}{ Filters } & \multicolumn{6}{|c|}{ PSNR of restored image in $\mathrm{dB}$} \\
\hline & $\begin{array}{l}10 \% \\
\text { Noise }\end{array}$ & $\begin{array}{l}20 \% \\
\text { Noise }\end{array}$ & $\begin{array}{l}30 \% \\
\text { Noise }\end{array}$ & $\begin{array}{l}40 \% \\
\text { Noise }\end{array}$ & $\begin{array}{l}50 \% \\
\text { Noise }\end{array}$ & $\begin{array}{l}60 \% \\
\text { Noise }\end{array}$ \\
\hline PWMAD & 34.86 & 30.58 & 25.94 & 22.41 & 19.42 & 17.08 \\
\hline ACWM filter & - & 36.07 & 32.59 & 28.79 & 25.19 & 21.19 \\
\hline AMF & 28.06 & 26.79 & 24.03 & 23.17 & 21.99 & - \\
\hline MDWCMMF & 31.14 & 28.16 & 26.08 & 24.45 & 22.96 & 21.46 \\
\hline Proposed & 27.02 & 27.20 & 25.77 & 24.49 & 23.28 & 22.07 \\
\hline
\end{tabular}




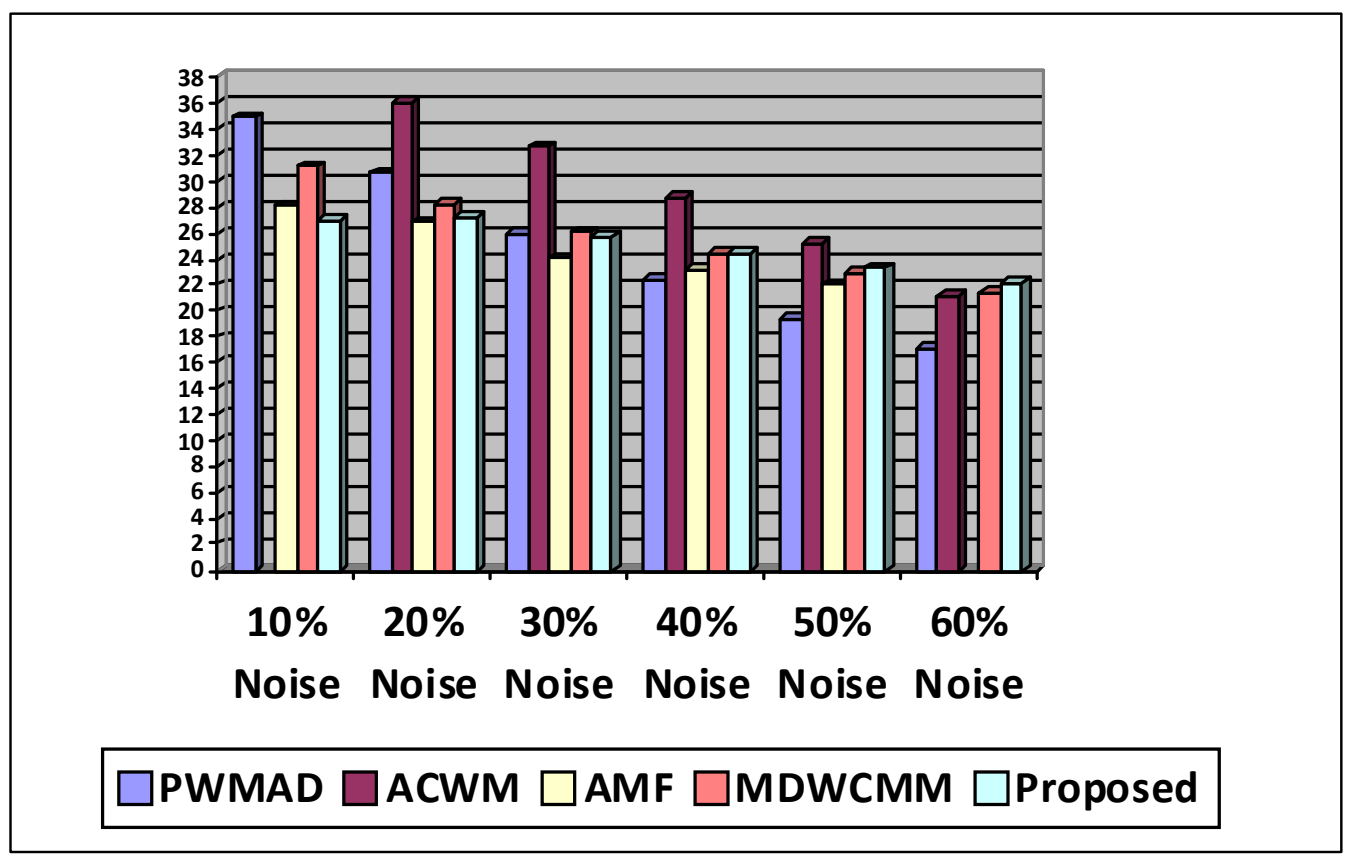

Figure 3:Comparison among various filters applied on gray Lenna corrupted with different levels of impulses

Table 2. Comparative results in PSNR of different algorithms applied to "Lenna" COLOR image corrupted by various rayes of Random-valued impulse noise

\begin{tabular}{|c|c|c|c|c|c|c|c|}
\hline \multirow{2}{*}{ Filters } & \multicolumn{6}{|c|}{ PSNR of restored image in dB } \\
\cline { 2 - 8 } & $\mathbf{3 \%}$ & $\mathbf{5 \%}$ & $\mathbf{1 0 \%}$ & $\mathbf{1 5 \%}$ & $\mathbf{2 0 \%}$ & $\mathbf{2 5 \%}$ & $\mathbf{3 0 \%}$ \\
\hline AVMF & 37.3 & 36.2 & 33.9 & 32.1 & 30.3 & 27.8 & 25.6 \\
\hline IIA & 34.3 & 33.5 & 30.6 & 27.3 & 24.9 & 23.5 & 22.0 \\
\hline MFF & 28.8 & 28.5 & 27.8 & 27.0 & 26.1 & 25.0 & 23.8 \\
\hline ATMED & 30.3 & 29.9 & 28.8 & 27.8 & 26.6 & 25.3 & 24.1 \\
\hline GMED & 31.2 & 31.0 & 30.1 & 29.3 & 28.2 & 26.7 & 25.3 \\
\hline TMAV & 31.0 & 30.7 & 29.8 & 28.7 & 27.4 & 25.9 & 24.5 \\
\hline FSB & 30.7 & 30.6 & 29.8 & 29.1 & 28.1 & 26.6 & 25.3 \\
\hline IFCF & 30.7 & 30.4 & 29.4 & 28.7 & 27.8 & 26.6 & 25.6 \\
\hline MIFCF & 30.9 & 30.6 & 29.4 & 28.5 & 27.4 & 26.1 & 25.0 \\
\hline EIFCF & 30.5 & 30.3 & 29.4 & 28.7 & 27.8 & 26.6 & 25.6 \\
\hline SSFCF & 30.3 & 30.1 & 29.3 & 28.4 & 27.1 & 25.6 & 24.2 \\
\hline
\end{tabular}


International Journal of Information Sciences and Techniques (IJIST) Vol.2, No.4, July 2012

\begin{tabular}{|c|c|c|c|c|c|c|c|}
\hline FIRE & 34.3 & 32.6 & 29.7 & 27.6 & 25.7 & 23.9 & 22.4 \\
\hline PWLFIRE & 31.1 & 28.8 & 25.5 & 23.4 & 21.7 & 20.4 & 19.1 \\
\hline DSFIRE & 30.5 & 28.6 & 25.8 & 24.1 & 22.7 & 21.6 & 20.6 \\
\hline FMF & 36.4 & 24.8 & 31.9 & 30.2 & 28.5 & 26.4 & 24.9 \\
\hline HAF & 29.6 & 29.2 & 27.8 & 26.6 & 25.2 & 24.0 & 22.7 \\
\hline AWFM & 31.3 & 30.8 & 29.3 & 28.0 & 26.2 & 24.7 & 23.1 \\
\hline MDWCMMF & 34.98 & 33.38 & 30.70 & 28.98 & 27.66 & 26.56 & 25.62 \\
\hline Proposed & 31.60 & 30.91 & 29.50 & 28.46 & 27.52 & 26.73 & 25.97 \\
\hline
\end{tabular}

Table 3. Comparative results in PSNR of different algorithms applied to various kinds of gray images corrupted with $40 \%$ of random-valued impulse noise

\begin{tabular}{|c|c|c|c|c|}
\hline \multirow{2}{*}{ Filters } & \multicolumn{4}{|c|}{ PSNR of restored image in dB } \\
\cline { 2 - 5 } & Elaine & Goldhill & Pepper & Airplane \\
\hline PWMAD & 24.66 & 24.16 & 24.63 & 24.37 \\
\hline Trilateral & 19.38 & 19.14 & 19.53 & 19.54 \\
\hline TSM & 20.26 & 20.02 & 20.14 & 19.37 \\
\hline MDWCMMF & 24.86 & 24.88 & 23.96 & 23.20 \\
\hline Proposed & 26.15 & 25.23 & 24.40 & 23.33 \\
\hline
\end{tabular}

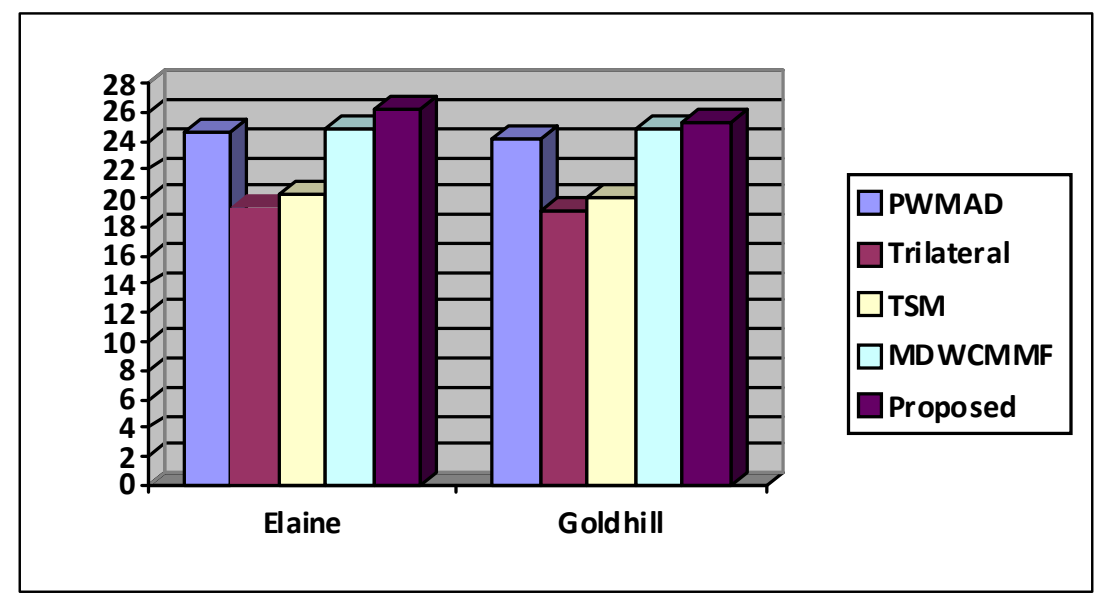

Figure 4. Comparison among various filters applied on various images corrupted with $40 \%$ noise 


\section{CONCLUSIONS}

In this paper, we proposed a median based directional cascaded with mask filter, for removal of random-valued impulse noise and compared the same with MDWCMMF[1]. It makes full use of the characteristics of impulses and edges to detect and restore noises. Simulation results showed that the filter performs better than various existing median-based filters in terms of subjective quality in restored images and in objective evaluations in terms of PSNR $(\mathrm{dB})$ and gives better results than MDWCMM filter in suppressing impulses from highly corrupted digital images.

\section{ACKNOWLEDGMENT}

The authors expressed deep sense of gratitude to the IIPC Project of AICTE, Government of India and to the department of CSE, University of Kalyani where the computational work has been carried out.

\section{REFERENCES}

[1] Mandal J.K., Sarkar A.,"A Modified Directional Weighted Cascaded-Mask Median Filter for Removal of Random Impulse Noise", Computer Science Proceedings in CSIT series, 26-27 May, 2012, The Second International Conference on Computer Science, Engineering and Application (CCSEA 2012).

[2] Yiqiu Dong and Shufang Xu , "A New Directional Weighted Median Filter for Removal of RandomValued Impulse Noise”,IEEE SIGNAL PROCESSING LETTERS, VOL. 14, NO. 3, MARCH 2007.

[3] T. Chen and H. R. Wu, "Adaptive impulse detection using center-weighted median filters," IEEE Signal Process. Lett., vol. 8, no. 1, pp. 1-3, Jan. 2001.

[4] V. Crnojevi'c, V. `Senk and `Z. Trpovski, "Advanced impulse detection based on pixel-wise MAD," IEEE Signal Processing Letters, vol. 11, pp. 589-592, 2004.

[5] Waqas Nawaz, Arfan Jaffar, and Ayyaz Hussain," Fast Directional Weighted Median Filter for Removal of Random-Valued Impulse Noise", 978-1-4244-8003-6/10/\$26.00 @2010 IEEE.

[6] X. Li and M. Orchard, "True edge-preserving filtering for impulse noise removal," in presented at the 34th Asilomar Conf. Signals, Syst. Comput.,Pacific Grove CA, Oct. 2000.

[7] Sheng-Fu Liang, Shih-Mao Lu, Jyh-Yeong Chang, Chin-Teng (CT) Lin , "A Novel Two-Stage Impulse Noise Removal Technique Based on Neural Networks and Fuzzy Decision" IEEE TRANSACTIONS ON FUZZY SYSTEMS, VOL. 16, NO. 4, AUGUST 2008863

[8] Wang H, Haddad R A, Adaptive median filters: New algorithms and results, IEEE Transactions on Image Processing, vol. 4, 1995, pp 499-502.

[9] Tao Chen, Kai-Kuang Ma and Li-Hui Chen (1999), 'Tri-State Median Filter for Image Denoising', IEEE Trans. on Image Processing, Vol. 8, No.8, pp.1-3, 1999.

[10] T. Chen and H. R. Wu, "Space variant median filters for the restoration of impulse noise corrupted images”, IEEE Trans. Circuits Syst. II, vol. 48, no. 8, pp. 784-789, Aug. 2001.

[11] W. K. Pratt, "Median filtering," Image Process. Inst., Univ. Southern California, Los Angeles, Sep. 1975, Tech. Rep..

[12] S. Zhang and M. A. Karim, "A new impulse detector for switching median filters," IEEE Signal Process. Lett., vol. 9, no. 11, pp. 360-363, Nov. 2002.

[13] Pankaj Kr. Sa, Ratnakar Dash, Banshidhar Majhi,"Second order difference based detection and directional weighted median filter for removal of random valued impulse noise", 4th IEEE International Conference on Industrial \& Information Science, 28-31 Dec. 2009.

[14] E. Abreu, M. Lightstone, S. K. Mitra, and K. Arakawa, "Anew efficient approach for the removal of impulse noise from highly corrupted images”, IEEE Trans. Image Process., vol. 5, no. 6, pp. 10121025, Jun. 1996.

[15] V. Crnojevic, V. Senk, and Z. Trpovski, "Advanced Impulse Detector Based on Pixel-Wise MAD" IEEE Signal Processing Letters, vol. 11, no. 7, pp.589-592, July 2004. 
[16] S. Schulte, V. D. Witte, M Nachtegael, D.V. D. Weken, and E.E. Kerre,'Fuzzy two-step filter for impuldse noise reduction from color images", IEEE transactions on image processing, vol. 15, no. 11, Nov. 2006.

[17] S. M. Guo, C. S. Lee, and C. Y. Hsu, "An intelligent image agent based on soft-computing techniques for color image processing”, Expert Syst. Appl., vol. 28, pp. 483-494, Apr 2005.

[18] F. Russo and G. Ramponi,"A fuzzy filter for image corrupted by impulse noise", IEEE Signal Processing Letters, vol. 3, no. 6, pp.168-170, Jun 1996.

[19] F. Russo, "Fire operators in image procesing", Fuzzy Sets and Syst., vol. 103, pp. 265-275,Apr 1999.

[20] F. Russo and G. Ramponi,"A noise smoother using cascaded FIRE filters", in proc. IEEE 4th Int. Conf. Fuzzy Systems, vol. 1, pp.351-358, Mar. 1995.

[21] K. Arakawa, "Median filter based on fuzzy rules and its application to image restoration", Fuzzy Sets and Syst., vol. 77, pp. 3-13, Jun 1996.

[22] H.K. Kwan, "Fuzzy filters for noise reduction in image", in Fuzzy filters for image processing, M. Nachtegael, D. Van der Weken, D. Van De Ville, and E. E. Eds, 1st Ed., Heidelberg, Germany: Physica Verlag, 2003, vol. 122, pp. 25-53.

[23] C. S. Lee, Y. H. Kuo, and P.T.Yu, "Weighted fuzzy mean filters for image processing", Fuzzy Sets and Syst., vol. 89, pp. 157-180, Jun 1997.

[24] F. Ferbiz, M. B. Menhaj, and S.A. Motamedi, "Edge preserving image filtering based on fuzzy logic", in proc. 6th EUFIT conf., 1998, pp. 1417-1421.

[25] H.G. Wang and H.C.Chiu, "An adaptive fuzzy filter for restoring highly corrupted images by histogram estimation”, in Proc. Nat. Sci. Council Part A, 1999, vol. 23, pp. 630-643.

[26] I. Kalaykov and G. Tolt, M M. Nachtegael, D. Van der Weken, D. Van De Ville, and E. E. Eds,"Realtime image noise cancellation based on fuzzy similarity", 1st Ed., Heidelberg, Germany: Physica Verlag, 2003, vol. 122, pp. 54-71.

[27] R. Lukac, “Adaptive vector median filter”, Pattern Recognit. Lett., vol. 24,pp. 1889-1899, Aug. 2003.

\section{Authors}

J. K. Mandal:M. Tech. ( Computer Science, University of Calcutta ), Ph.D. ( Engg., Jadavpur University ) in the field of Data Compression and Error Correction Techniques, Professor in the dept. of Computer Science and Engineering, University of Kalyani, India. Life member of Computer Society of India since 1992 and life member of Cryptography Research Society of India. Dean faculty of Engineering, Technology \& Management, working in the field of Network Security, Steganography, Remote sensing \& GIS Application, and Image Processing. He has 25 years of teaching and research experiences. Eight Scholars awarded Ph.D. one submitted and 8 are pursuing. Total no. of publications is more than 230 in addition of publication of five books from LAP, Germany.

Aparna Sarkar:Ms. Aparna Sarkar is pursuing M.Tech in Computer Science and Engineering from University of Kalyani in the department of Computer Science and Engineering. She obtained her B.Sc $(\mathrm{H})$ degree in Computer Science and MCA degree from University of Kalyani in 2007 and 2010 respectively. She has 4 publications in her credit.
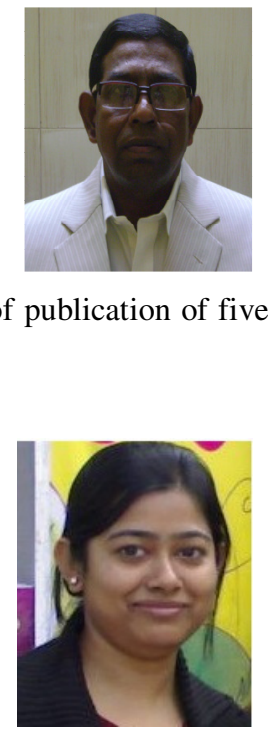